\title{
An Infant with Both Cystic Fibrosis and Coeliac Disease
}

\author{
DAVID W. HIDE and DAVID BURMAN \\ From Department of Paediatrics, Bristol Royal Hospital for Sick Children, Bristol
}

Coeliac disease (gluten enteropathy) and cystic fibrosis are both diagnosed fairly often in paediatric practice. The incidence of coeliac disease in London was estimated in 1959 as 1 in 3000 (Carter, Sheldon, and Walker, 1959), but this is almost certainly an underestimate, for the data were collected before the routine use of jejunal biopsy enabled the condition to be diagnosed more accurately. A figure of 1 in 1778 was found in Glasgow (Black, 1964), and this estimate has recently been confirmed (McCrae, 1968). Recent figures for cystic fibrosis give an incidence of 1 in 2448 live births in Australia (Danks, Allan, and Anderson, 1965) and 1 in 1863 in the United States (Honeyman and Siker, 1965). The chances of both conditions occurring together in one patient is thus extremely remote, but the boy reported here satisfies the current criteria for making both diagnoses. We know of no other report in the literature of the disorders coexisting.

\section{Case History}

A male infant, born on 7 March 1967, after an uneventful pregnancy lasting 39 weeks was the first child of non-consanguineous parents. At birth he weighed $2.7 \mathrm{~kg}$., and from the first day of life he developed loose stools from which Pseudomonas pyocyanaeas were cultured. He gained weight extremely slowly on a fullcream milk, and cereals were added to his diet at the age of 4 weeks. At the age of 12 weeks he was admitted to Bristol Royal Hospital for Sick Children for investigation of his failure to thrive.

On examination he was marasmic with a grossly distended abdomen (Fig. 1a), and was continually passing frequent bulky, pale stools. Relevant investigations showed $\mathrm{Hb} 10.6$ g., with normal red cell morphology. His 5-day faecal fat excretion was $18 \cdot 4 \mathrm{~g}$. per day and the levels of stool tryptic activities were $6,7,21,1$, and 2 units (Azocasein; normal is above 10 units). Microscopy of the stools revealed no abnormality, culture was negative, the stool $\mathrm{pH}$ was between 6 and 7 , and the sugar chromatogram was negative. The $\beta$-lipoproteins in the blood were normal. Duodenal aspirate

Received February 11, 1969. showed a tryptic activity of 2 units (Azocasein) and an amylase activity of 1600 Somogyi units per $100 \mathrm{ml}$. A chest $x$-ray showed some overdistension of the lung bases, with increased lung markings in these regions but no specific abnormality.

Clinical course. During the weeks after admission when the baby was being investigated, he developed at different times a coliform septicaemia, dysentery due to Shigella sonnei, and a chest infection from which no specific organism was grown.

Though usually excessively hungry he failed to gain weight (Fig. 2). This, together with a low stool tryptic activity and low enzyme activity in the duodenal juice, led to a clinical diagnosis of cystic fibrosis. At the age of 17 weeks, the first jejunal biopsy was per-

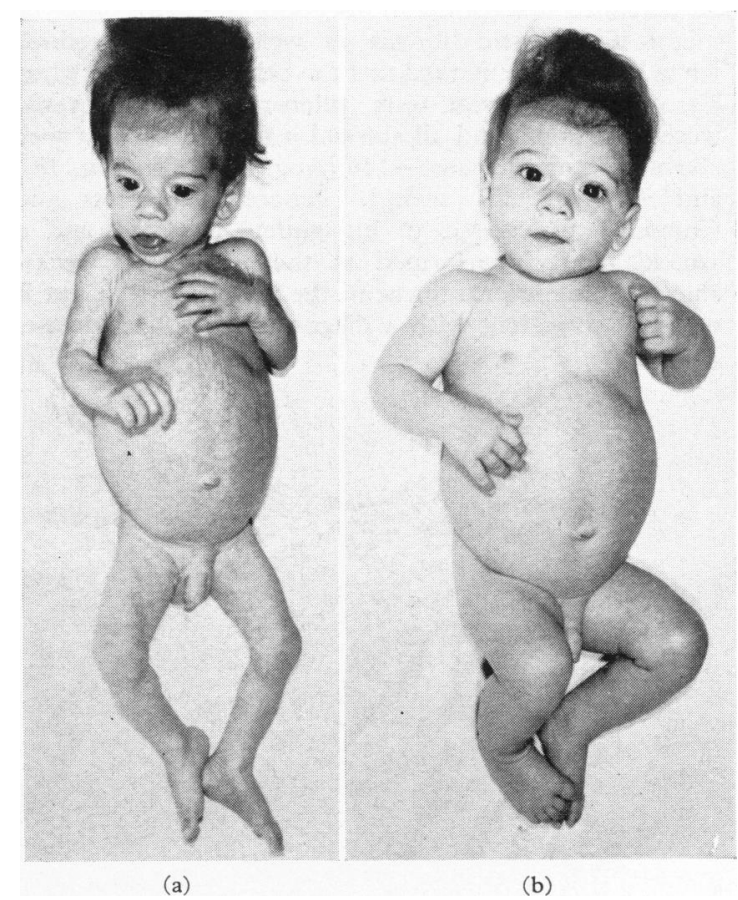

Fig. 1.-Patient (a) before treatment, aged 4 months, and (b) after 3 months on a gluten-free diet, aged 7 months. 


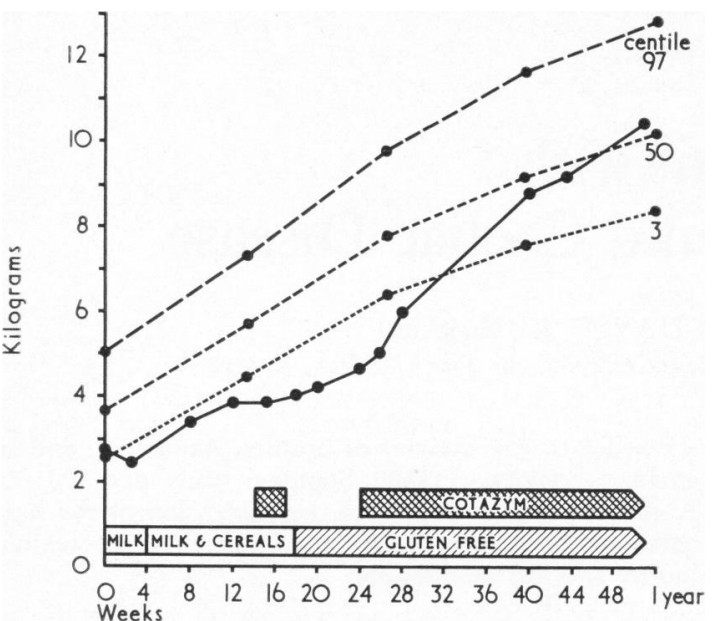

FIG. 2.-Weight chart of patient showing response to treatment.

formed by a technique already described (Burman, 1963). This showed villous atrophy, slight cellular infiltration of the lamina propria, changes in the epithelial cells, and an absent brush border characteristic of coeliac disease (Fig. 3). At the age of 18 weeks, a gluten-free diet was started and he responded with an impressive gain in weight (Fig. 1b, Fig. 2). However, he remained susceptible to infections, and fears that he might have cystic fibrosis as well were entertained when his father remarked that the baby tasted salty when kissed. Three sweat tests (pilocarpine iontophoresis) were then done, and all showed a sodium content well above the normal range-146 (Aug. 15), 164 (Aug. 18), and 90 (Aug. 29) mEq/l. Pancreatic extracts and vitamins were added to his gluten-free diet, and a second biopsy, performed at the age of 30 weeks, showed some improvement in the villous pattern but it was still consistent with a diagnosis of coeliac disease.
The repeat duodenal juice taken on this occasion contained minimal tryptic activity. The steatorrhoea had reduced to $6.8 \mathrm{~g}$. per day. Treatment with Cotazym, vitamins, fucidic acid, and a gluten-free diet continued, and progress was satisfactory, so that at the age of 1 year he was over the 50th centile for weight and height. He occasionally still had minor chest infections and wheezing.

During the second year of life he developed normally apart from a pot-belly, and at the age of 21 months was at the 75th centile for weight and the 50th for height. In order to confirm both diagnoses, two further sweat sodiums were estimated and were 72 and $86 \mathrm{mEq} / 1$. He was challenged with gluten, and after 2 biscuits and a sausage sandwich he developed frequent foul-smelling stools, abdominal discomfort, and became irritable and miserable. His parents were unwilling to continue him on a gluten-containing diet.

\section{Discussion}

The diagnosis of cystic fibrosis seems incontrovertible. The steatorrhoea, liability to infection, low duodenal and faecal trypsin, and raised sweat sodium satisfy the usual diagnostic criteria. In our experience, the intestinal mucosa in this condition does not show the changes found in coeliac disease. In infants, we have in fact found these changes only in coeliac disease, though experimentally they have been noted to follow repeated applications of irritating substances to enterostomies (Townley, Cass, and Anderson, 1964). A similar appearance has also been reported after neomycin (Jacobson, Prior, and Falcon, 1960). The changes in the small gut mucosa in malnutrition and bowel infections have previously been investigated and do not show the changes found in coeliac disease or in this baby (Burman, 1965).

The dramatic improvement after withdrawal of

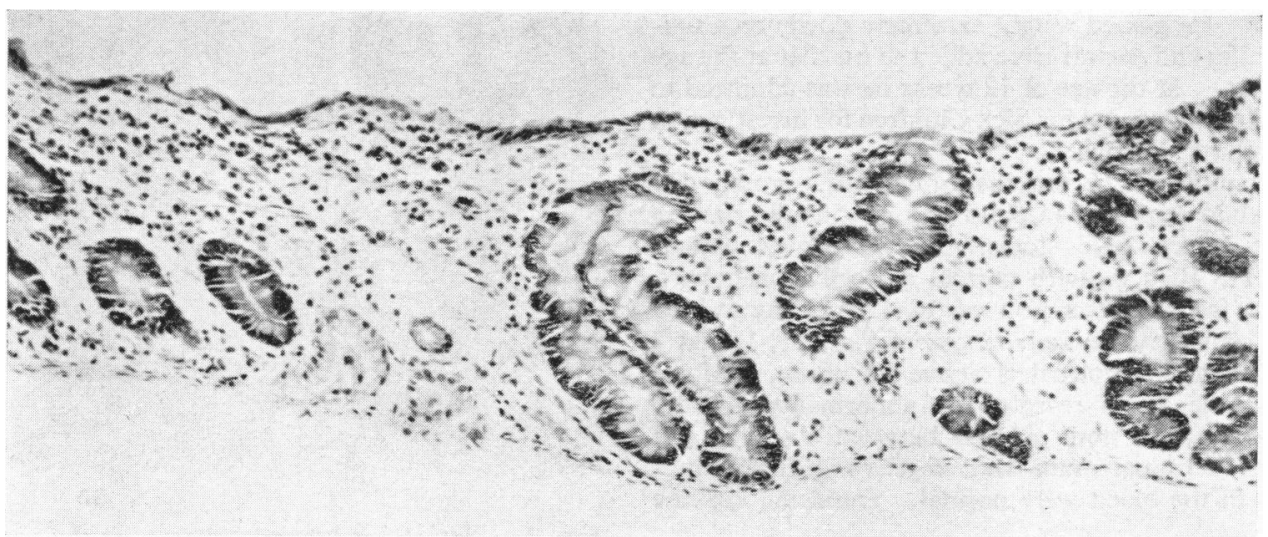

Fig. 3.-First jejunal biopsy showing coeliac change. (H. and E. $\times 170$.) 
gluten from the diet, together with the typical biopsy changes on two occasions, support the diagnosis of coeliac disease. The immediate relapse on reintroducing gluten further supports this diagnosis, and we believe that this child has both conditions.

\section{Summary}

An infant with failure to thrive was shown by jejunal biopsy and response to gluten-free diet to have coeliac disease and by examination of sweat electrolytes and duodenal juice to have cystic fibrosis. This association has not previously been reported. He responded well to treatment of both conditions.

We are very grateful to Dr. Walford Harrison for the histology reports and photomicrograph, and to the Department of Medical Illustration of the United Bristol Hospitals for the other illustrations.

\section{REFERENCES}

Black, J. A. (1964). Possible factors in the incidence of coeliac disease. Acta paediat. (Uppsala), 53, 109.

Burman, D. (1963). Celiac disease. I. Diagnosis by jejunal biopsy. Clin. Pediat. (Philad.), 2, 581.

- (196j). The jejunal mucosa in kwashiorkor. Arch. Dis. Childh., 40, 526.

Carter, C., Sheldon, W., and Walker, C. (1959). The inheritance of coeliac disease. Ann. hum. Genet., 23, 266.

Danks, D. M., Allan, J., and Anderson, C. M. (1965). A genetic study of fibrocystic disease of the pancreas. ibid., 28, 323.

Honeyman, M. S., and Siker, E. (1965). Cystic fibrosis of the pancreas; an estimation of the incidence. Amer. F. hum. Genet., 17,461 .

Jacobson, E. D., Prior, J. T., and Falcon, W. W. (1960). Malabsorptive syndrome induced by neomycin: morphologic alterations in the jejunal mucosa. F. Lab. clin. Med., 56, 245.

McCrae, W. M. (1968). The malabsorption syndrome. Matern. Child Care, 4, 31.

Townley, R. R. W., Cass, M. H., and Anderson, C. M. (1964). Small intestinal mucosal patterns of coeliac disease and idiopathic steatorrhoea seen in other situations. Gut, 5,51 .

Correspondence to Dr. David Burman, Department of Paediatrics, Bristol Royal Hospital for Sick Children, Bristol 2. 